\title{
Assessment of SARS-CoV-2 Infection Prevalence in Homeless Shelters - Four U.S. Cities, March 27-April 15, 2020
}

\begin{abstract}
Emily Mosites, $\mathrm{PhD}^{1}$; Erin M. Parker, $\mathrm{PhD}^{1}$; Kristie E. N. Clarke, $\mathrm{MD}^{1}$; Jessie M. Gaeta, MD ${ }^{2,3}$; Travis P. Baggett, MD ${ }^{2,4,5}$; Elizabeth Imbert, MD ; Madeline Sankaran, $\mathrm{MPH}^{7}$; Ashley Scarborough, $\mathrm{MPH}^{7}$; Karin Huster, $\mathrm{MPH}^{8}$; Matt Hanson, $\mathrm{MD}^{8}$; Elysia Gonzales, $\mathrm{MPH}^{8}$; Jody Rauch, $\mathrm{MA}^{8}$; Libby Page, $\mathrm{MPH}^{8}$; Temet M. McMichael, $\mathrm{PhD}^{8,9}$; Ryan Keating, $\mathrm{MPH}^{1}$; Grace E. Marx, MD ${ }^{1}$; Tom Andrews, MBA ${ }^{10}$; Kristine Schmit, MD ${ }^{1}$; Sapna Bamrah Morris, MD ${ }^{1}$; Nicole F. Dowling, PhD ${ }^{1}$; Georgina Peacock, MD ${ }^{1}$; COVID-19 Homelessness Team
\end{abstract}

\section{On April 22, 2020, this report was posted as an MMWR Early Release on the MMWR website (https://www.cdc.gov/mmwr).}

In the United States, approximately 1.4 million persons access emergency shelter or transitional housing each year (1). These settings can pose risks for communicable disease spread. In late March and early April 2020, public health teams responded to clusters (two or more cases in the preceding 2 weeks) of coronavirus disease 2019 (COVID-19) in residents and staff members from five homeless shelters in Boston, Massachusetts (one shelter); San Francisco, California (one); and Seattle, Washington (three). The investigations were performed in coordination with academic partners, health care providers, and homeless service providers. Investigations included reverse transcription-polymerase chain reaction testing at commercial and public health laboratories for SARS-CoV-2, the virus that causes COVID-19, over approximately 1-2 weeks for residents and staff members at the five shelters. During the same period, the team in Seattle, Washington, also tested residents and staff members at 12 shelters where a single case in each had been identified. In Atlanta, Georgia, a team proactively tested residents and staff members at two shelters with no known COVID-19 cases in the preceding 2 weeks. In each city, the objective was to test all shelter residents and staff members at each assessed facility, irrespective of symptoms. Persons who tested positive were transported to hospitals or predesignated community isolation areas.

Overall, 1,192 residents and 313 staff members were tested in 19 homeless shelters (Table). When testing followed identification of a cluster, high proportions of residents and staff members had positive test results for SARS-CoV-2 in Seattle (17\% of residents; $17 \%$ of staff members), Boston (36\%; $30 \%)$, and San Francisco (66\%; 16\%). Testing in Seattle shelters where only one previous case had been identified in each shelter found a low prevalence of infection (5\% of residents; $1 \%$ of staff members). Among shelters in Atlanta where no cases had been reported, a low prevalence of infection was also identified ( $4 \%$ of residents; $2 \%$ of staff members). Community incidence in the four cities (the average number of reported cases in the county per 100,000 persons per day during the testing period) varied, with the highest (14.4) in Boston and the lowest (5.7) in San Francisco (2).
The findings in this report are subject to at least three limitations. First, testing represented a single time point. Second, although testing all residents and staff members at each shelter was the objective, some were not available or declined (e.g., in San Francisco 143 of an estimated 255 residents at risk were tested). Finally, symptom information for persons tested was not consistently available and thus not included, although symptom information from Boston is available elsewhere.*

Homelessness poses multiple challenges that can exacerbate and amplify the spread of COVID-19. Homeless shelters are often crowded, making social distancing difficult. Many persons experiencing homelessness are older or have underlying medical conditions $(1,3)$, placing them at higher risk for severe COVID-19-associated illness (4).

To protect homeless shelter residents and staff members, CDC recommends that homeless service providers implement recommended infection control practices, apply social distancing measures including ensuring residents' heads are at least 6 feet ( 2 meters) apart while sleeping, and promote use of cloth face coverings among all residents. ${ }^{\dagger}$ These measures become especially important once ongoing COVID-19 transmission is identified within communities where shelters are located. Given the high proportion of positive tests in the shelters with identified clusters and evidence for presymptomatic and asymptomatic transmission of SARS-CoV-2 (5), testing of all residents and staff members regardless of symptoms at shelters where clusters have been detected should be considered. If testing is easily accessible, regular testing in shelters before identifying clusters should also be considered. Testing all persons can facilitate isolation of those who are infected to minimize ongoing transmission in these settings.

\section{Acknowledgments}

Homeless service provider leadership and staff members; participating residents; Margaret Lukoff, Public Health - Seattle \& King County; Joanna Eveland, John C. Fremont Healthcare District; San Francisco COVID-19 Response Team; Public Health Seattle King County COVID-19 Investigation Team.

\footnotetext{
${ }^{*}$ https://www.medrxiv.org/content/10.1101/2020.04.12.20059618v1.

${ }^{\dagger}$ https://www.cdc.gov/coronavirus/2019-ncov/community/homeless-shelters/ plan-prepare-respond.html.
} 
TABLE. SARS-CoV-2 testing among residents and staff members at 19 homeless shelters in four U.S. cities with community transmission of COVID-19, March 27-April 15, 2020

\begin{tabular}{|c|c|c|c|c|c|c|}
\hline \multirow[b]{2}{*}{ City } & \multirow{2}{*}{$\begin{array}{c}\text { No. of } \\
\text { shelters assessed }\end{array}$} & \multirow[b]{2}{*}{ Date of testing } & \multicolumn{2}{|c|}{ Residents } & \multicolumn{2}{|c|}{ Staff members } \\
\hline & & & No. tested & No. (\%) positive & No. tested & No. (\%) positive \\
\hline \multicolumn{7}{|c|}{ Shelters reporting $\geq 2$ cases in 2 weeks preceding testing } \\
\hline Seattle & 3 & Mar 30-Apr 8 & 179 & $31(17)$ & 35 & $6(17)$ \\
\hline Boston & 1 & Apr 2-3 & 408 & $147(36)$ & 50 & $15(30)$ \\
\hline San Francisco & 1 & Apr 4-15 & 143 & $95(66)$ & 63 & $10(16)$ \\
\hline Subtotal & 5 & March 30-Apr 15 & 730 & $273(37)$ & 148 & $31(21)$ \\
\hline \multicolumn{7}{|c|}{ Shelters reporting 1 case in 2 weeks preceding testing } \\
\hline Seattle & 12 & Mar 27-Apr 15 & 213 & $10(5)$ & 106 & $1(1)$ \\
\hline \multicolumn{7}{|c|}{ Shelters reporting no cases in 2 weeks preceding testing } \\
\hline Atlanta & 2 & Apr 8-9 & 249 & $10(4)$ & 59 & $1(2)$ \\
\hline Total & 19 & Mar 27-Apr 15 & 1,192 & $293(25)$ & 313 & $33(11)$ \\
\hline
\end{tabular}

Abbreviation: COVID-19 = coronavirus disease 2019.

\section{COVID-19 Homelessness Team}

Ann Buff, CDC COVID-19 Emergency Response; Calla Jamison, CDC COVID-19 Emergency Response; Ruthanne Marcus, CDC COVID-19 Emergency Response; Carol Y. Rao, CDC COVID-19 Emergency Response; Julie L. Self, CDC COVID-19 Emergency Response; Farrell Tobolowsky, CDC COVID-19 Emergency Response; Samantha Williams, CDC COVID-19 Emergency Response; Meagan Kay, Public Health Seattle \& King County, Naveena Bobba, San Francisco Department of Public Health; Stephanie Cohen, San Francisco Department of Public Health; Jonathan Fuchs, San Francisco Department of Public Health; Trang Nguyen, San Francisco Department of Public Health; Julie Stoltey, San Francisco Department of Public Health.

Corresponding author: Emily Mosites, lwx7@cdc.gov, 907-346-0570.

${ }^{1}$ CDC COVID-19 Emergency Response; ${ }^{2}$ Boston Health Care for the Homeless Program; ${ }^{3}$ Boston Medical Center; ${ }^{4}$ Massachusetts General Hospital, Boston, Massachusetts; ${ }^{5}$ Harvard Medical School, Boston, Massachusetts; ${ }^{6}$ University of California San Francisco; ${ }^{7}$ San Francisco Department of Public Health; ${ }^{8}$ Public Health - Seattle \& King County, Washington; ${ }^{9}$ Epidemic Intelligence Service, CDC; ${ }^{10}$ St. Joseph's Health System, Atlanta, Georgia.

All authors have completed and submitted the International Committee of Medical Journal Editors form for disclosure of potential conflicts of interest. Travis Baggett reports receipt of royalties from UpToDate for authorship of a topic review on health care of homeless persons in the United States. No other potential conflicts of interest were disclosed.

\section{References}

1. US Department of Housing and Urban Development. 2017 annual homeless assessment report to Congress. Part 1: point-in-time estimates of homelessness. Washington, DC: US Department of Housing and Urban Development; 2017. https://www.hudexchange.info/ resource/5639/2017-ahar-part-1-pit-estimates-of-homelessness-in-the-us/

2. USAFacts. Confirmed cases dataset. Seattle, WA: USAFacts; 2020. https:// usafacts.org/visualizations/coronavirus-covid-19-spread-map/

3. Fazel S, Geddes JR, Kushel M. The health of homeless people in highincome countries: descriptive epidemiology, health consequences, and clinical and policy recommendations. Lancet 2014;384:1529-40. https:// doi.org/10.1016/S0140-6736(14)61132-6

4. CDC COVID-19 Response Team. Preliminary estimates of the prevalence of selected underlying health conditions among patients with coronavirus disease 2019-United States, February 12-March 28, 2020. MMWR Morb Mortal Wkly Rep 2020;69:382-6. https://doi.org/10.15585/ mmwr.mm6913e2

5. Kimball A, Hatfield KM, Arons M, et al.; Public Health - Seattle \& King County; CDC COVID-19 Investigation Team. Asymptomatic and presymptomatic SARS-CoV-2 infections in residents of a long-term care skilled nursing facility - King County, Washington, March 2020. MMWR Morb Mortal Wkly Rep 2020;69:377-81. https://doi.org/10.15585/ mmwr.mm6913e1 